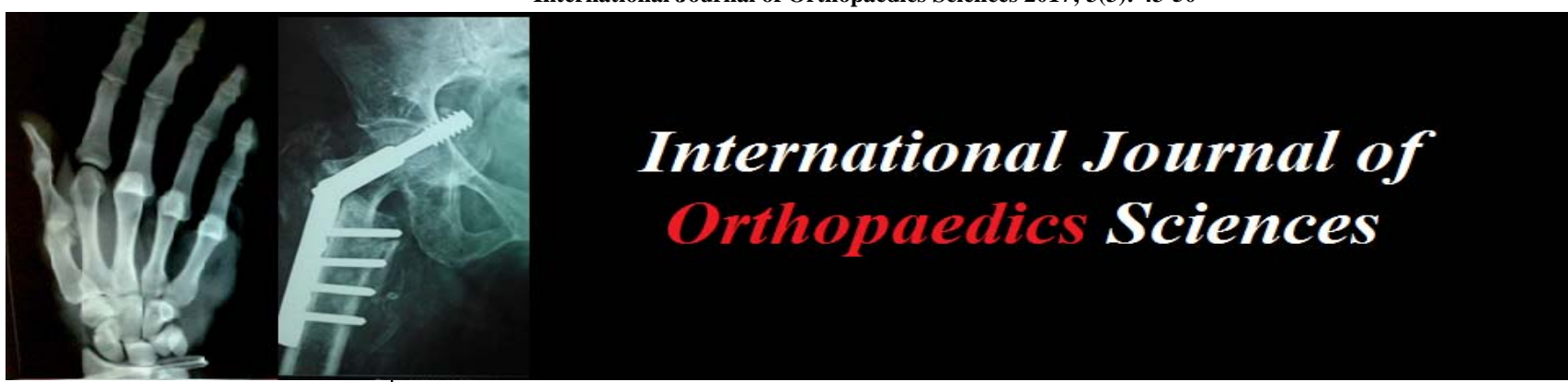

ISSN: $2395-1958$

IJOS 2017; 3(3): 43-50

(C) 2017 IJOS

www.orthopaper.com

Received: 10-05-2017

Accepted: 11-06-2017

Dr. M Venkataramana Rao Professor \& Unit Chief,

Department of Orthopaedics, SSIMS \& RC Davanagere,

Karnataka, India

Dr. Tejus DB

Resident, Department of

Orthopaedics, SSIMS \& RC

Davanagere, Karnataka, India

Dr. J Manjunath

Professor and head, Department of Orthopaedics, SSIMS \& RC

Davanagere, Karnataka, India

Dr. AG Karibasappa

Professor \& Unit Chief,

Department of Orthopaedics,

SSIMS \& RC Davanagere,

Karnataka, India
Correspondence

Dr. Tejus DB

Resident, Department of

Orthopaedics, SSIMS \& RC

Davanagere, Karnataka, India

\section{A prospective study on clinical outcome following surgically managed displaced clavicle fractures using pre-contoured locking plate and screws}

\author{
Dr. M Venkataramana Rao, Dr. Tejus DB, Dr. J Manjunath and Dr. AG \\ Karibasappa
}

DOI: $\underline{\text { http://dx.doi.org/10.22271/ortho.2017.v3.i3a.10 }}$

\section{Abstract}

Background: Most acute displaced clavicular fractures conventionally have been treated non-operatively with the expectation of a high probability of fracture union, good functional outcomes, and a high level of patient satisfaction. However, the outcome of non-operative treatment is not as favorable as once thought and there has been a growing trend to treat these fractures surgically. We studied the clinical outcome of displaced clavicle fractures managed surgically by pre-contoured locking plate and screws. Materials \& methods: A prospective study was carried out between October 2015 and June 2017 in SS Institute of Medical Sciences \& Research Centre Davanagere, Karnataka where 50 patients with displaced clavicle fractures were treated surgically by pre-contoured locking plate $\&$ screws. They were followed up for a minimum period of 2 years by the main author and evaluated for clinical outcome using dash score and constant moreley score.

Results: Out of 50 cases 42 cases had excellent results without complications \& 5 patients had good result without complications. 2 cases which were going for delayed union were treated with bone grafting and 1 case, where the plate was exposed on the medial aspect at 2 months follow up, plate was removed and wound was closed in layers.

Conclusion: In our study of displaced clavicle fractures, which were effectively treated surgically with pre-contoured locking plate $\&$ screws gave excellent results \& to be considered one of the best surgical modality for displaced clavicle fracture management.

Keywords: Displaced clavicle fracture, pre contoured LCP, dash score, constant morely score

\section{Introduction}

Aim of the study

1. To study the fracture union at interval of 3months 6 months and 12 months follow up.

2. To assess the functional status of the patient following surgery.

3. To assess the subjective status of the patient following surgery.

4. To determine the complications following the surgery.

Materials \& methods: A prospective study was carried out between october 2015 and june 2017 in SS Institute Of Medical Sciences \& Research Centre, Davanagere, Karnataka where 50 patients with displaced clavicle fractures were treated surgically by pre-contoured locking plate $\&$ screws. They were followed up for a minimum period of 2 years by the main author and evaluated for clinic-functional outcome using DASH score and constant moreley score. A written consent for participation in this prospective study was obtained from all patients. Most of patients were in the age group between 21 and 40 years (63\%). The youngest was 18 years and oldest was 59 years with an average age of 32.1 years. There were 38 males and 12 females. 46 of the fractures were sustained following Road Traffic Accident (92\%) and 4 cases (8\%) following fall from height. Right clavicle was fractured in 28 cases and left in 21 cases and bilateral clavicle fracture in 1 patient. 42 cases had comminution at fracture site. All the cases had displace- ment more than $2 \mathrm{~cm}$. On an average the timing of surgery was 1 days post injury. 13 cases had associated injuries. 
6 patients had rib fractures, 1 had scapula fracture, 2 cases had tibia fracture, 1 case had patella fracture and 2 cases had facial bone fractures. Patients with isolated clavicle fracture were in hospital for 5 days. Those patients requiring treatment for associated major injuries stayed for long time ranging from 14 days to 44days.

All the cases were operated with precontoured locking plate fixed on superior surface with $3.5 \mathrm{~mm}$ locking screws. Interfragmentary screw was used in 27 cases.

Demographic details of patients

\begin{tabular}{|c|c|}
\hline Age & 18-59yrs (32.1) \\
\hline Sex & 38M:12F \\
\hline Mode of injury & 46 \\
RTA & 4 \\
Fall from height & 28 \\
Laterality & 21 \\
Right & 1 \\
Left & 42 \\
Bilateral & 50 \\
\hline Communition & $1-7$ days \\
\hline Allman type 1
\end{tabular}

\section{Inclusion criteria}

- $\quad$ Age $>18 y r$.

- Displaced clavicle fractures (Allman group I, II, III)

- A fracture that had occurred less than two weeks previously.

- Bilateral clavicle fractures

- Clavicle fractures associated with neurovascular injury

Exclusion criteria: Haemopneumothorax

- Multiple rib fractures

- Flail chest

\section{Operative technique}

Patient in supine position with a sand bag placed behind the ipsilateral scapula. Parts were painted and draped under strict aseptic precaution. An oblique incision (approximately 8$10 \mathrm{~cm}$ ) was made over the fracture site. Larger branches of the identifiable supraclavicular nerves were identified and protected throughout the procedure; smaller branches were sacrificed at the surgeon's discretion. Precontoured locking plate with $3.5 \mathrm{~mm}$ locking screws were used. Fixation was performed following a reduction with minimal periosteal stripping. Three screws were used in the medial and lateral areas, whichever case was possible.

Postoperatively, the patients were given a simple sling for approximately 2 weeks, and pendulum exercise and active range of motion exercise were then started.

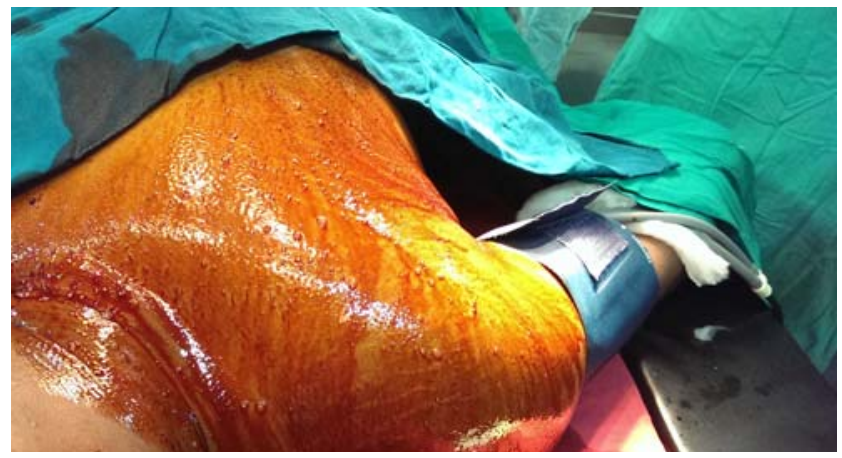

Patient in supine position, parts painted \& draped.

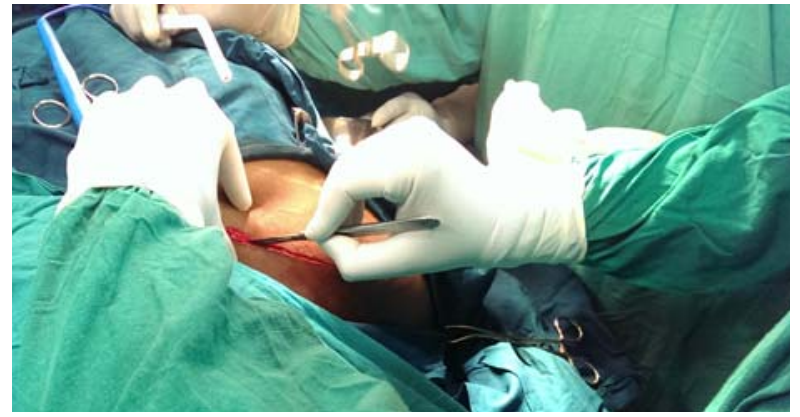

Incision

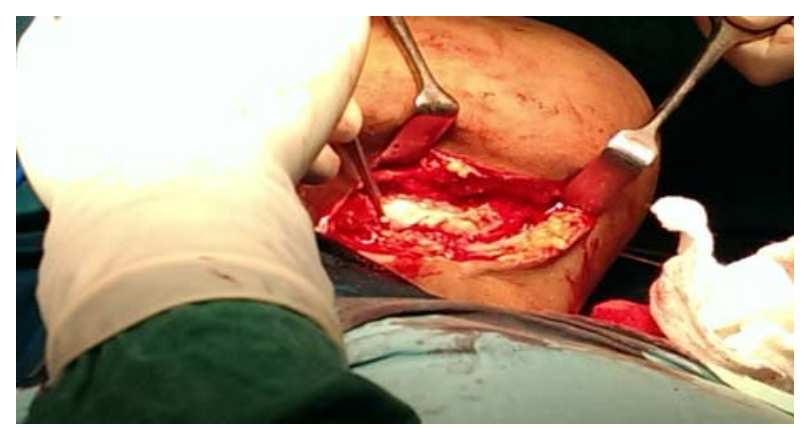

Soft tissue dissection and bone exposure

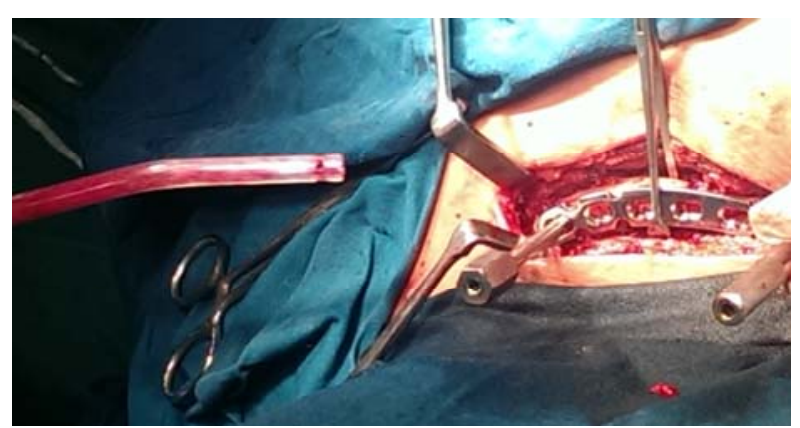

Fracture fragments reduced and plate placed with drill sleeve

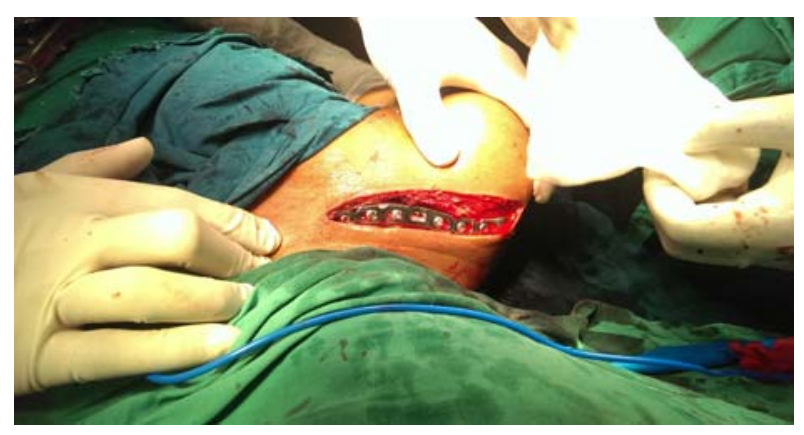

Fracture fixed with precontoured LCP \& screws.

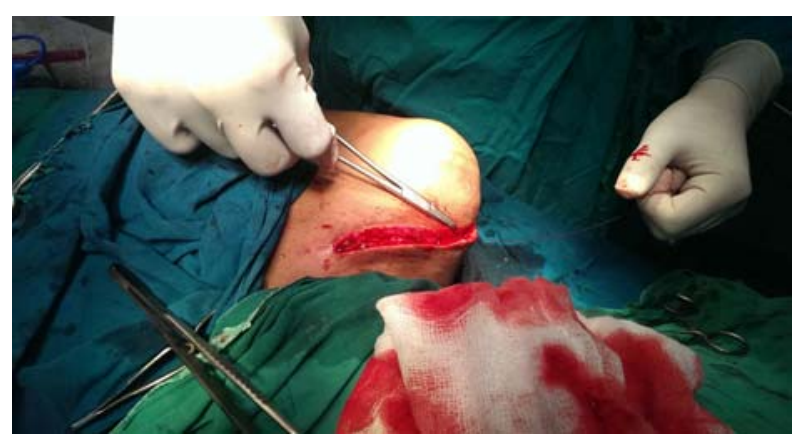

Wound closed in layers. 


\section{Operative Instruments}

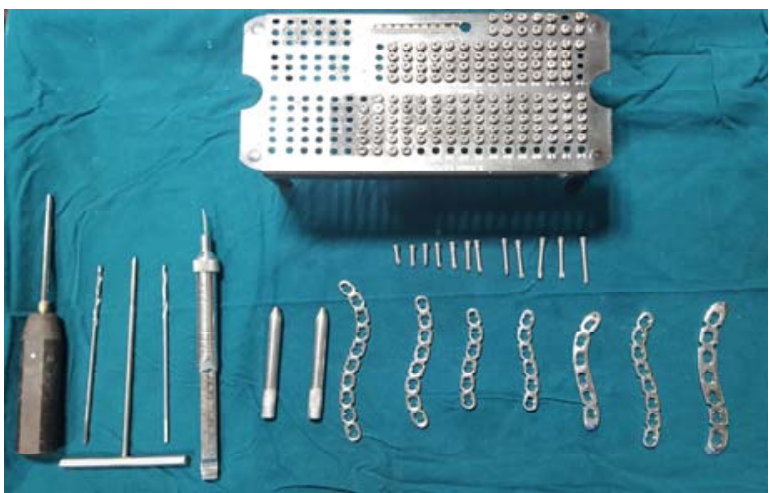

Screw driver

3.0 Drill bits

Depth Gauge

Sleeves

$3.5 \mathrm{~mm}$ Pre-contoured locking compression plates

$3.5 \mathrm{~mm}$ Screws and screw box

\section{Result}

Fifty patients volunteered to participate and signed the written informed consent. All of them completed the study. Demographic data are shown in table 1 . The mean operative time was $48 \mathrm{~min}$ (range, 30 to $66 \mathrm{~min}$ ). Bony union was achieved in 48 cases after surgery at an average of 12 weeks (range, 8 to 24 weeks). These Patients returned to their daily routine activities from the time of injury on an average of 14 weeks (range, 8 to 20 weeks). 2 cases presented with signs of delayed union at 8 weeks, which were augumented with illiac bone graft and these fractures united by 24 weeks. 1 patient had plate exposed on the medial side (wound dehiscence) with signs of infection when presented at 8 weeks of follow up. The plate was removed. On table, the fracture was already uniting, adequate wound debridement was done and the infected granulation tissue was sent for culture and sensitivity.
Culture reports showed positive for Staphylococcus aureus \& specific iv antibiotics was started. Secondary wound suturing was done once the culture sent came as negative.

Postoperative complications were noted in the follow up. The complications were dysesthesia in the area of the incision in two cases, painful shoulder in three cases. Patients were specifically questioned about their satisfaction or dissatisfaction regarding the appearance of the healed surgical scar, appearance of shoulder. 9 patients had dissatisfaction regarding the healed surgical scar. None of the patients were dissatisfied by the appearance of shouder in the follow up.

\begin{tabular}{|c|c|}
\hline Operation time & 30-66min (48) \\
\hline Bone union & 8 -24 weeks(12) \\
\hline Return to activity & 8 -20weeks(14) \\
\hline Complications & 2 \\
Dysthesia & 1 \\
Wound dehiscence & 0 \\
Hypertrophic scar & 3 \\
Painfull shoulder & 0 \\
Motion limitation & 41 \\
\hline Satisfaction with appearence & $3.1-5.3(4.2)$ \\
\hline Dash score & $85-90(87.5)$ \\
\hline Constant morely score &
\end{tabular}
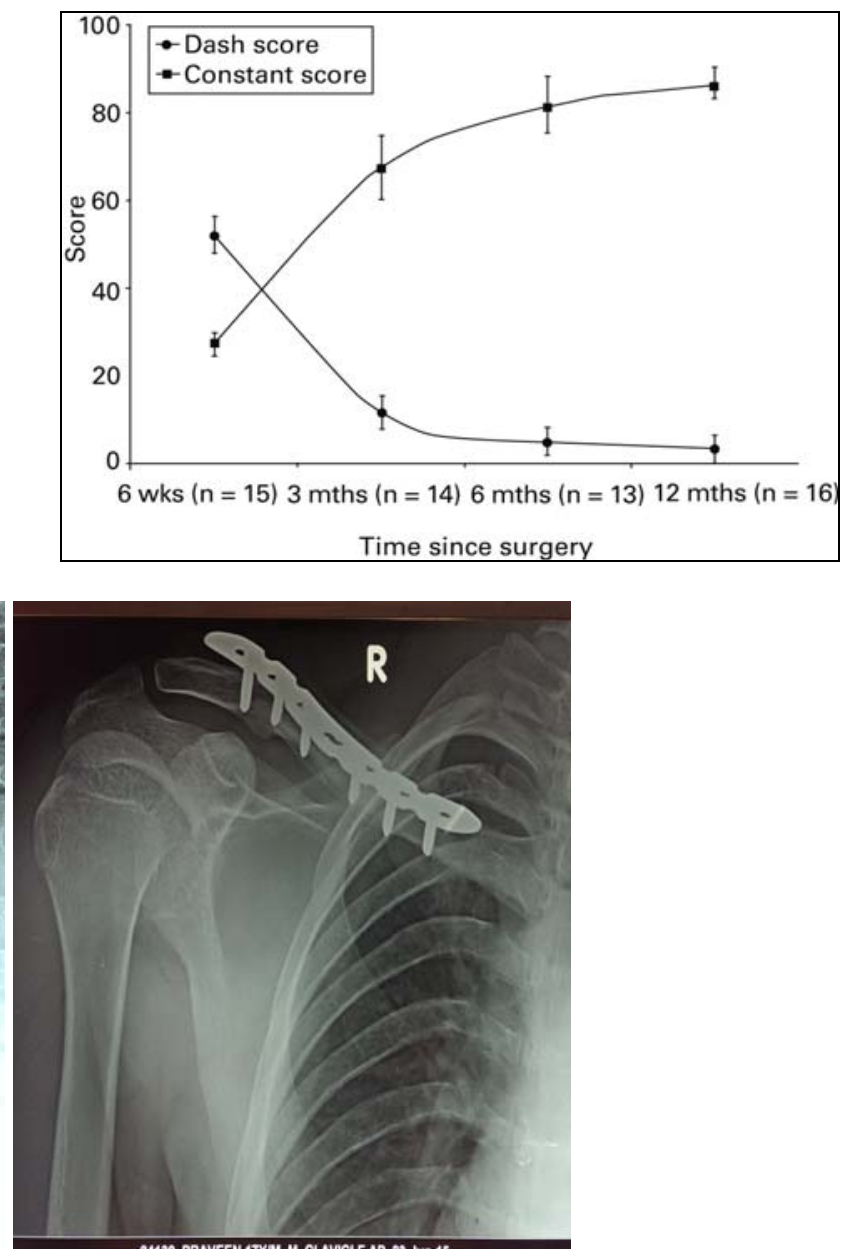

19yr male with closed displaced middle $1 / 3^{\text {rd }}$ clavicle fracture with post op check xray with pre-contoured lcp \& screws 


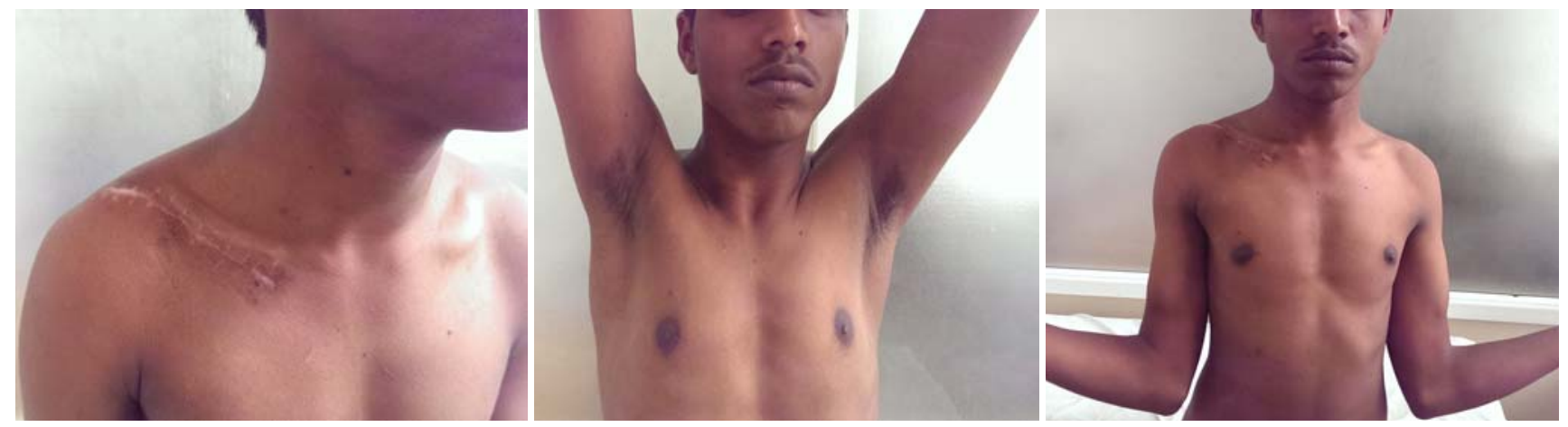

Clinical picture depicting full range of movements

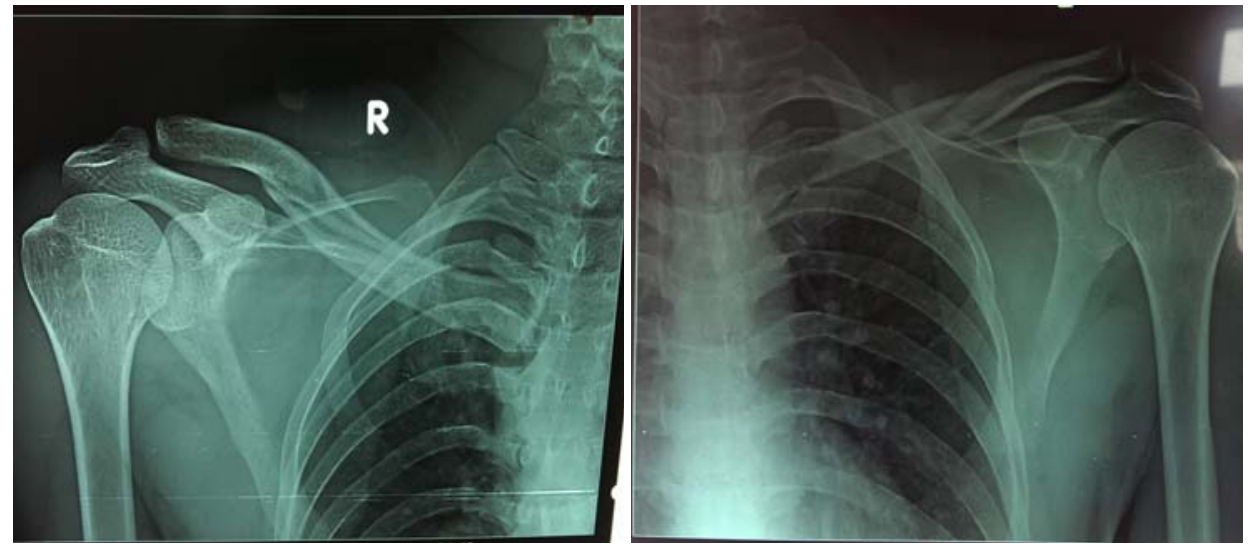

$32 \mathrm{yr}$ male with $\mathrm{b} / 1$ closed communited middle $1 / 3^{\text {rd }}$ clavicle fracture

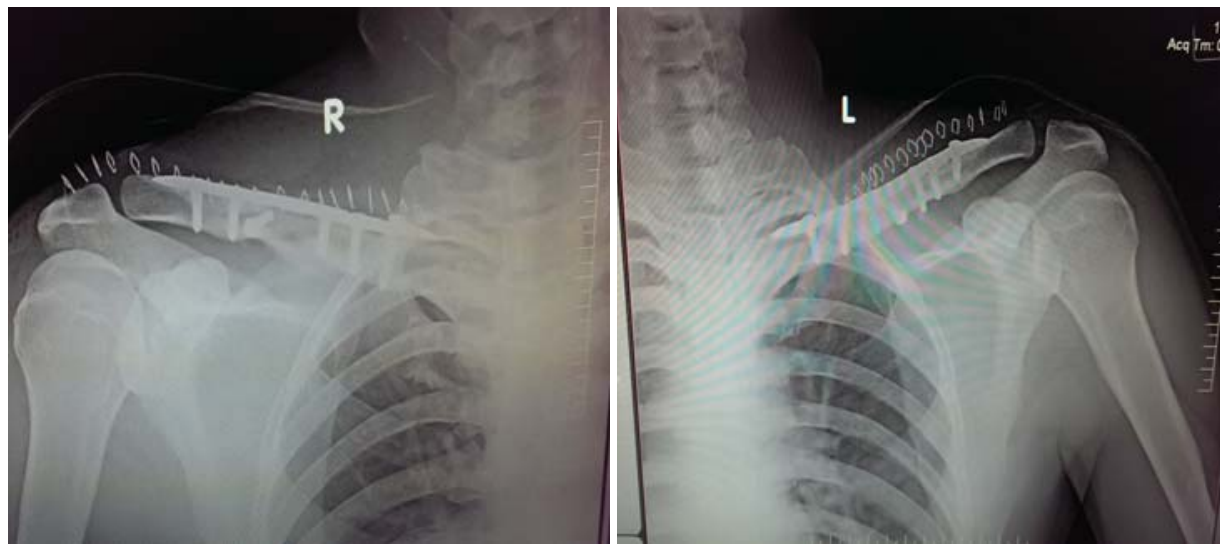

Post operative check xray with precontoured LCP \& lag screw fixation
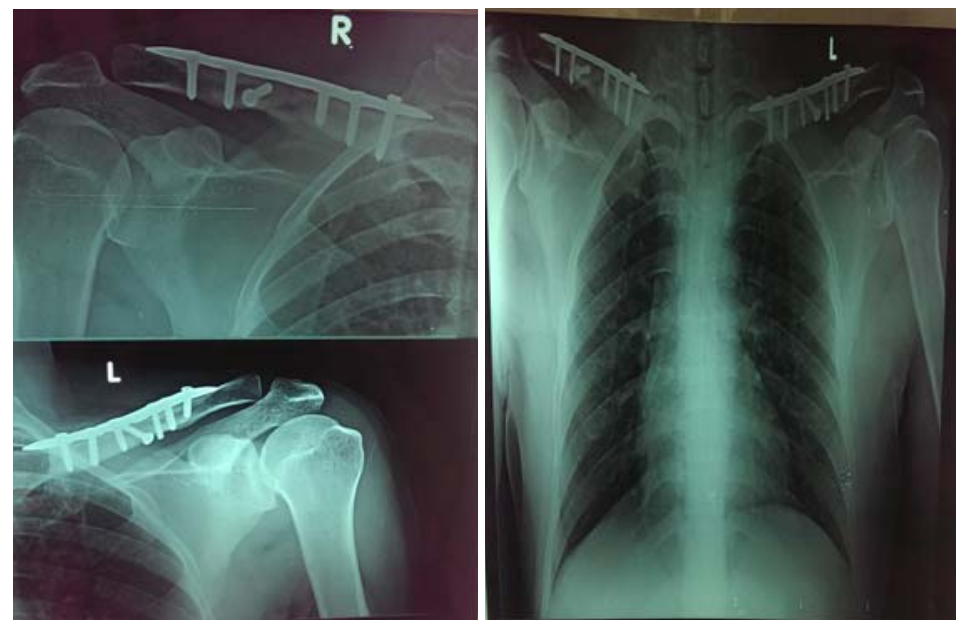

Follow up check xrays at 1 month $\& 3$ months $\sim 46 \sim$ 

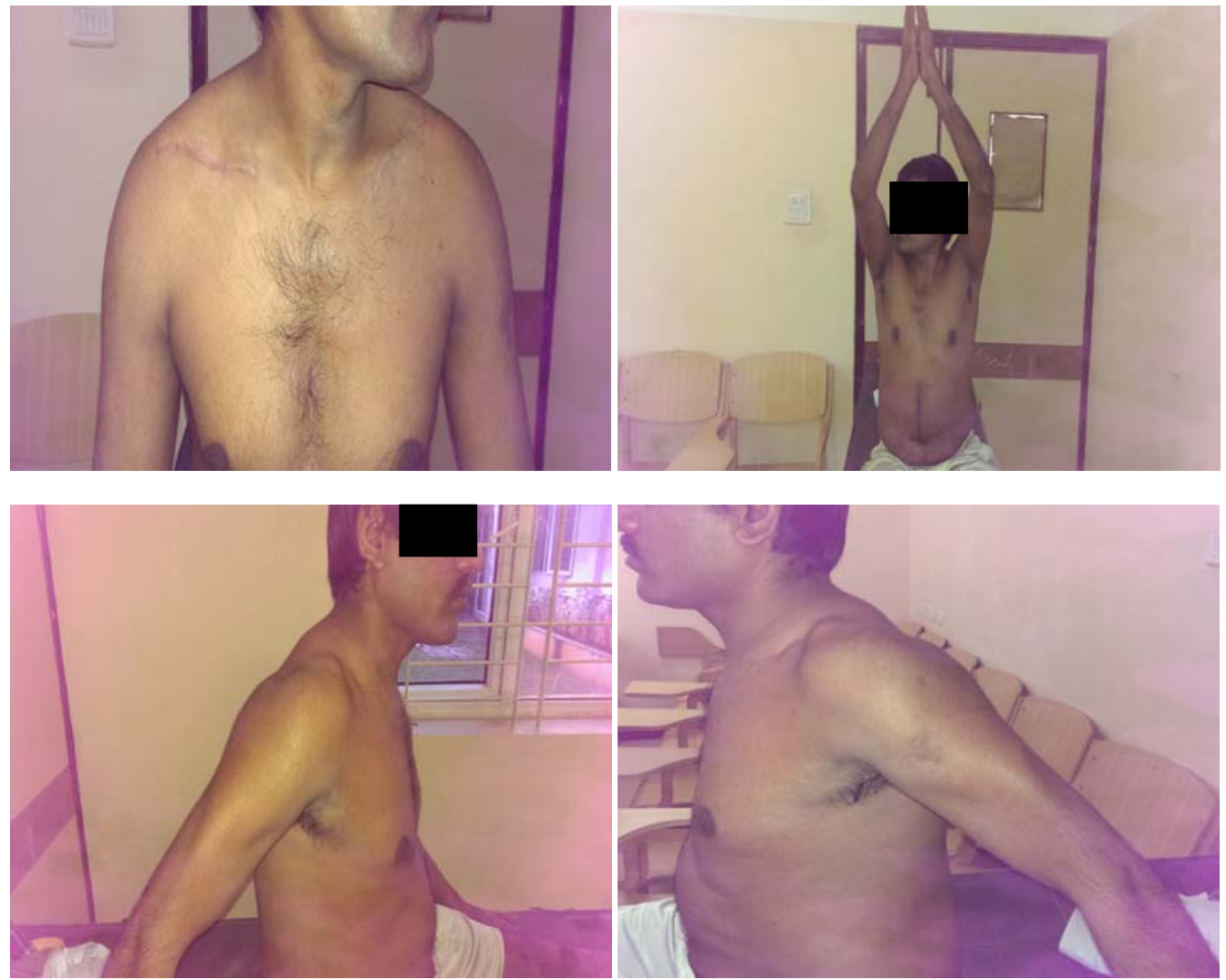

Clinical picture showing full ROM of both shoulder joints at follow up

22 yr male with closed communited middle $1 / 3^{\mathrm{RD}}$ left clavicle fracture treated with pre-contoured lcp \& screw. immediate post op xray
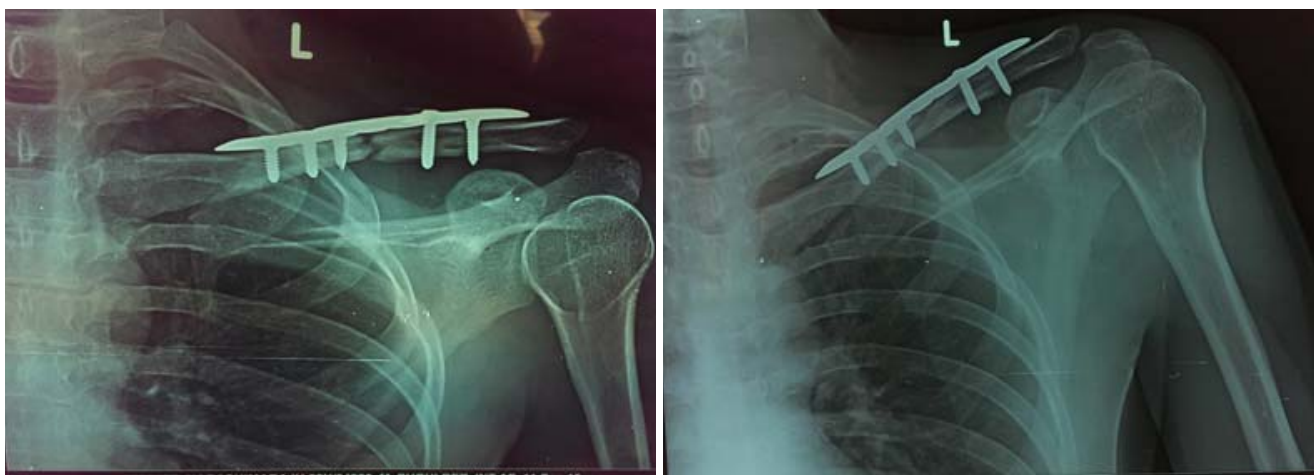

Follow up at 8 weeks showing gap in fracture site going for delayed union. Xray of patient after bone grafting was done on follow up.

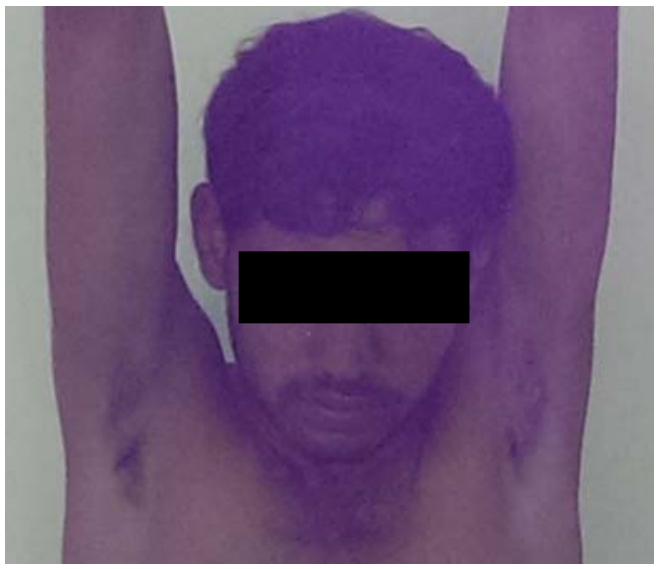

Clinical picture of the same patient showing overhead abduction $\sim 47 \sim$ 


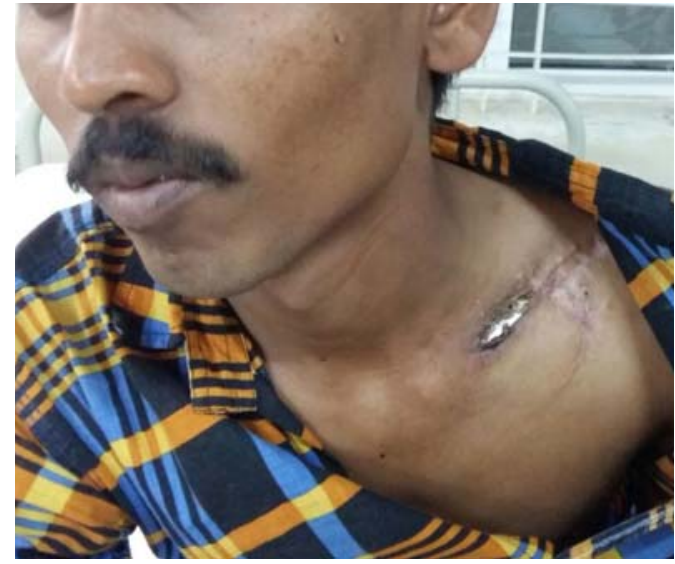

$27 \mathrm{yr}$ male who was treated with precontoured locking plate and screws for closed right clavicle fracture. The patient didn't turn up for routine follow up. The patient presented to opd with plate exposed medially at 8 weeks post op with signs of infection.

$2^{\text {nd }}$ picture dipicting uniting clavicle fracture, where plate and screws were removed and wound debridement was done

\section{Discussion}

The clavicle acts as a strut, which transfers power from the trunk to the arm. The clavicle is S-shaped with a medial convexity and a lateral concavity. The middle third is the thinnest part of the clavicle and is located directly under the skin with no soft tissue or muscle attachment. Thus, it is vulnerable to direct and indirect trauma. This explains the high frequency of fractures in the middle third.

Fractures of the clavicular shaft were considered to be a domain of non-operative treatment for a long time. This dogma was based on the studies conducted by NEER CS and Rowe CR in the 1960s. However, recent studies have shown that the rate of malunion and non-union after non-operative treatment might well be much higher than previously shown. Subjective contentment with the results of non-operative treatment is not uniformly high. In 2007, the Canadian Orthopaedic Trauma Society reported that internal fixation with plates resulted in more rapid union, excellent clinical outcomes, and lower complication rates in 132 patients with displaced clavicle fractures than non-operative treatments. Hence, there has been increasing interest in surgical treatments with open reduction and internal fixation.

The operative methods for the treatment of clavicle midshaft fractures involve intramedullary K-wire fixation or Steinmann pin fixation or elastic stable intramedullary nailing and plate fixation. The procedures using the former two materials result in low resistance to torque, carry risks of pin loosening and infection, and require a long-term fixation period. In addition, Elastic stable intramedullary nailing leads to good cosmetic and functional results. Patients profit from marked postoperative pain reduction and a rapid recovery of range of motion in the shoulder joint. However, multifragmentary fractures or oblique fractures can lead to a telescoping of the fracture site. This leads to a postoperative length reduction. To prevent this complication, Elastic stable intramedullary nailing is only recommended for simple or displaced wedge fractures.

Open reduction and internal fixation with plates (plate osteosynthesis) is still the standard method for the surgical treatment of clavicular shaft fractures. The goal of surgical treatment is the anatomic reduction with reconstruction of

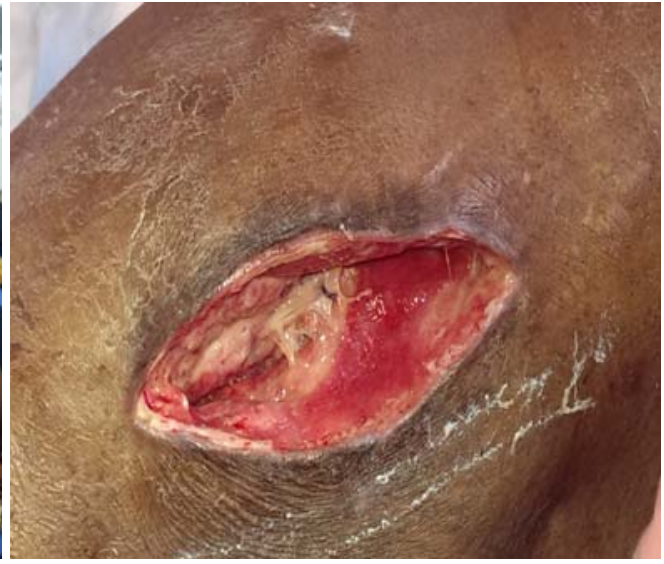

clavicular length and alignment of the shoulder girdle. To prevent early stress fracture of the implant, a fairly strong implant in comparison to the bone strength should be chosen. Pre-contoured LCP have been preferred for plate osteosynthesis of the clavicle. The advantages of Precontoured LCP include strong fixation due to locking between the screw and plate, and blood supply preservation due to minimal contact between plate and cortical bone. When LCP are used to treat clavicle midshaft fractures, the risks of injury to the subclavicular artery or brachial plexus could potentially be reduced because fixation can be achieved without the tip of the screw reaching the opposite bone cortex and periosteal stripping can be minimized to promote rapid union. It is believed that the surgery time can be reduced using LCP because accurate plate contouring is not necessary and periosteal stripping could be minimized using self-tapping screws. Surgical treatment of displaced midclavicular fractures with pre-contoured locking compression plate and screws, which can be shaped to match the shape of the clavicle, can be effective in the treatment of clavicle midshaft fractures. However, there remains some problem such as increased soft tissue stripping, infections, extensive scars, supraclavicular nerve injury.

\section{Conclusion}

In our study of 50 cases of displaced clavicle fractures, we conclude that 47 patients had excellent outcome as deduced by dash score \& constant morely score. 2 patients had complication of delayed union and 1 patient had plate exposure medially with signs of infection.

The surgical procedure is easy, less time consuming, less amount of intraoperative bleeding, with no requirement of fluroscopic usage and surgeon friendly. The pre-contoured LCP helps to achieve anatomical reduction with an excellent end result of bony union by retaining the normal ' $S$ ' shape of the clavicle. The patients have no limitation of motion of the shoulder joint and can return to their full daily routine activities as soon as 8 weeks. Majority of the patients have no subjective complaints.

Though there are various surgical methods for fracture clavicle fixation, our study and other published series has shown that open reduction internal fixation with minimal periosteal stripping using pre-contoured locking plate \& screws is far superior compared to other surgical modalities. So clavicle fracture fixation with precontoured lcp and screws can be considered the best modality and this is going to stay for a long period in orthopaedic practice. 


\section{References}

1. Johnson EW, Collins HR. Non-union of the clavicle. Arch Surg. 1963; 87(6):963-6.

2. Paffen PJ, Jansen EW. Surgical treatment of clavicular frac- tures with Kirschner wires: a comparative study. Arch Chir Neerl. 1978; 30(1):43-53.

3. Khan LA, Bradnock TJ, Scott C et al. Fractures of the clavicle. J Bone Joint Surg Am. 2009; 91:447-60.

4. Nordqvist A, Petersson C. The incidence of fractures of the clavicle. Clin Orthop Relat Res. 1994; 300:127-32.

5. Postacchini F, Gumina S, De Santis $\mathrm{P}$ et al. Epidemiology of clavicle fractures. J Shoulder Elbow Surg. 2002; 11:452-6.

6. Hill JM, McGuire MH, Crosby LA. Closed treatment of displaced middle-third fractures of the clavicle gives poor results. J Bone Joint Surg Br. 1997; 79:537-9.

7. Nowak J, Holgersson M, Larsson S. Sequelae from clavicular fractures are common. Acta Orthop. 2005; 76:496-502.

8. Chu CM, Wang SJ, Lin LC. Fixation of mid-third clavicular frac- tures with knowles pins: 78 patients followed for 2-7 years. Acta Orthop Scand. 2002; 73:134-9.

9. Chuang TY, Ho WP, Hsieh PH et al. Closed reduction and internal fixation for acute midshaft clavicular fractures using cannulated screws. J Trauma. 2006; 60:1315-20.

10. Shen WJ, Liu TJ, Shen YS. Plate fixation of fresh displaced midshaft clavicle fractures. Injury. 1999; 30:497-500.

11. Robinson CM, Court-Brown CM, McQueen MM et al. Estimating the risk of non-union following non-operative treatment of a clavicular fracture. J Bone Joint Surg Am. 2004; 86:1359-65.

12. Smekal V, Irenberger A, Struve $\mathrm{P}$ et al. Elastic stable intramedullary nailing versus non-operative treatment of dis- placed midshaft clavicular fractures-a randomized, controlled, clinical trial. J Orthop Trauma 2009; 23:10612.

13. Chul CH, Song KS, Min BW et al. operative treatment of clavicle midshaft fractures: comparison between reconstruction plate and locking compression plate. Clin Orthop Surg. 2010; 2:154-9.

14. Smekal V, Irenberger A, Attal RE et al. Elastic stable intramedullary nailing is best for mid-shaft clavicular frac- tures without comminution: results in 60 patients. Injury. 2011; 42:324-9.

15. Yian EH, Ramappa AJ, Arneberg O et al. The Constant score in normal shoulders. J Shoulder Elbow Surg. 2005; 14:128-33.

16. Hudak PL, Amadio PC, Bombardier C. Development of an upper $\square$ extremity outcome measure: the DASH (disabilities of the arm, shoulder and hand) [corrected]. The Upper Extremity Collabo- rative Group (UECG). Am J Ind Med. 1996; 29:602-8.

17. Beaton DE, Wright JG, Katz JN. Development of the QuickDASH: comparison of three item-reduction approaches. J Bone Joint Surg Am. 2005; 87:1038-46.

18. Neer 2nd CS. Non-union of the clavicle. J Am Med Assoc. 1960; 172:1006-11.

19. Rowe CR. An atlas of anatomy and treatment of midclavicular fractures. Clin Orthop Relat Res. 1968; 58:29-42.

20. Zlowodzki M, Zelle BA, Cole PA et al. Treatment of acute mid- shaft clavicle fractures: systematic review of
2144 fractures: on behalf of the Evidence-Based Orthopaedic Trauma Working Group. J Orthop Trauma. 2005; 19:504-7.

21. Kettler M, Schieker M, Braunstein V et al. Flexible intramedullary nailing for stabilization of displaced midshaft clavicle fractures: technique and results in 87 patients. Acta Orthop. 2007; 78:424-9.

22. Canadian Orthopaedic Trauma Society. Non-operative treat- ment compared with plate fixation of displaced midshaft clavicular fractures. A multicenter, randomized clinical trial. J Bone Joint Surg Am. 2007; 89:1-10.

23. Post M. Current concepts in the treatment of fractures of the clavicle. Clin Orthop Relat Res. 1989; 245:89-101.

24. Jubel A, Andermahr J, Faymonville $\mathrm{C}$ et al. Reconstruction of shoulder-girdle symmetry after midclavicular fractures. Sta- ble, elastic intramedullary pinning versus rucksackbandage. Chirurg. 2002;73:978-81.

25. Meier C, Grueninger P, Platz A. Elastic stable intramedullary nailing for midclavicular fractures in athletes: indications, technical pitfalls and early results. Acta Orthop Belg. 2006; 72:269-75.

26. Walz M, Kolbow B, Auerbach F. Elastic, stable intramedullary nailing in midclavicular fractures-a change in treat- mentstrategies? Unfallchirurg. 2006; 109:200-11.

27. Lee YS, Lin CC, Huang CR et al. Operative treatment of mid- clavicular fractures in 62 elderly patients: knowles pin versus plate. Orthopedics. 2007; 30:959-64.

28. Smekal V, Oberladstaetter J, Struve $P$ et al. Shaft fractures of the clavicle: current concepts. Arch Orthop Trauma Surg. 2009; 129:807-15.

29. Haidukewych GJ. Innovations in locking plate technology. J Am Acad Orthop Surg. 2004; 12:205-12.

30. Perren SM. Evolution and rationale of locked internal fixa- tor technology. Introductory remarks. Injury 2001; 32(2):B3-9.

31. Gautier E, Sommer C. Guidelines for the clinical application of the LCP. Injury, 2003; 34(2):B63-76.

32. Fernandez Dell Oca AA. The principle of helical implants. Unusual ideas worth considering. Injury. 2002; 33(1):SA1-27.

33. Lau TW, Leung F, Chan CF et al. Minimally invasive plate osteosynthesis in the treatment of proximal humeral fracture. Int Orthop. 2007; 31(5):657-64.

34. Zhiquan A, Bingfang Z, Yeming W et al. Minimally inva- sive plating osteosynthesis (MIPO) of middle and distal third humeral shaft fractures. J Orthop Trauma 2007; 21(9):628-33.

35. Moseley HF. The clavicle: its anatomy and function. Clin Orthop. 1968; 58:17-27.

36. Rowe CR. An atlas of anatomy and treatment of midclavicular fractures. Clin Orthop. 1968; 58:29-42.

37. Robinson CM. Fractures of the clavicle in the adult. Epidemiology and classification. J Bone Joint Surg Br. 1998; 80:476-484

38. Neer CS. II Fractures of the distal third of the clavicle. Clin Orthop Relat Res. 1968; 58:43-50.

39. Hill JM, McGuire MH, Crosby LA. Closed treatment of displaced middle-third fractures of the clavicle gives poor results. J Bone Joint Surg Br. 1997; 79:537-541.

40. McKee MD, Pedersen EM, Jones C. Deficits following nonoperative treatment of displaced midshaft clavicular fractures. J Bone Joint Surg Am. 2006; 88:35-40.

41. Mullaji AB, Jupiter JB. Low-contact dynamic compression plating of the clavicle. Injury. 1994; 25:41- 
45.

42. tHuang JL, Toogood P, Chen MR, Wilber JH, Cooperman DR. Clavicular anatomy and the applicability of precontoured plates. J Bone Joint Surg Am. 2007; 89:2260-2265.

43. Robertson C, Celestre P, Mahar A, Schwartz A. Reconstruction plates for stabilization of mid-shaft clavicle fractures: differences between nonlocked and locked plates in two different positions. J Shoulder Elbow Surg. 2009; 18:204-209.

44. Eden Lars, Doht Stefanie, Frey Sönke P. Biomechanical comparison of the locking compression superior anterior clavicle plate with seven and ten hole reconstruction plates in midshaft clavicle fracture stabilization. Int Orthopaedics. 2012; 36:2537-2543.

45. Hundekar BB. Internal fixation of displaced middle third fractures of clavicle with precontoured locking plate. Hundekar BB. J Orthop. 2013; 15;10(2):79-85.

46. Sang Ki Lee MD, Jae Won Lee MD, Dae Geon Song MD, Won Sik Choy MD. Precontoured Locking Plate Fixation for Displaced Lateral Clavicle Fractures. 